\title{
Low-level mechanical vibration enhances osteoblastogenesis via a canonical Wnt signaling-associated mechanism
}

\author{
HEQI GAO ${ }^{1 *}$, MINGMING ZHAI $^{*}$, PAN WANG ${ }^{1}$, XUHUI ZHANG $^{1}$, JING CAI $^{2}$, \\ XIAOFEI CHEN ${ }^{3}$, GUANGHAO SHEN ${ }^{1}$, ERPING LUO ${ }^{1}$ and DA JING ${ }^{1}$ \\ ${ }^{1}$ Department of Biomedical Engineering, Fourth Military Medical University; ${ }^{2}$ Department of \\ Endocrinology, Xijing Hospital, Fourth Military Medical University, Xi'an, Shaanxi 710032; ${ }^{3}$ Department of \\ Biomedical Engineering, Bethune International Peace Hospital, Shijiazhuang, Hebei 050082, P.R. China
}

Received October 27, 2015; Accepted November 23, 2016

DOI: $10.3892 / \mathrm{mmr} .2017 .6608$

\begin{abstract}
Osteoporosis is a skeletal metabolic disease characterized by reduced bone mass and a high susceptibility to fractures, in which osteoblasts and osteoclasts are highly involved in the abnormal bone remodeling processes. Recently, low-magnitude, high-frequency whole-body vibration has been demonstrated to significantly reduce osteopenia experimentally and clinically. However, the underlying mechanism regarding how osteoblastic activity is altered when bone tissues adapt to mechanical vibration remains elusive. The current study systematically investigated the effect and potential molecular signaling mechanisms in mediating the effects of mechanical vibration $\left(0.5 \mathrm{~g}_{\mathrm{n}}, 45 \mathrm{~Hz}\right)$ on primary osteoblasts in vitro. The results of the present study demonstrated that low-level mechanical stimulation promoted osteoblastic proliferation and extracellular matrix mineralization. In addition, it was also revealed that mechanical vibration induced improved cytoskeleton arrangement in primary osteoblasts. Furthermore, mechanical vibration resulted in significantly increased gene expression of alkaline phosphatase, bone morphogenetic protein 2 and osteoprotegerin, and suppressed sclerostin gene expression, as determined by reverse transcription-quantitative polymerase chain reaction (RT-qPCR) analyses. Mechanical vibration was observed to upregulate gene and protein expression levels of osteogenesis-associated biomarkers, including osteocalcin and Runt-related transcription factor 2. In addition, RT-qPCR
\end{abstract}

Correspondence to: Dr Da Jing or Professor Erping Luo, Department of Biomedical Engineering, Fourth Military Medical University, 169 Changle West Road, Xi'an, Shaanxi 710032, P.R. China

E-mail: jingdaasq@126.com

E-mail: luoerping@fmmu.edu.cn

*Contributed equally

Key words: osteoblasts, mechanical vibration, extracellular matrix mineralization, canonical Wnt signaling, osteoporosis and western blotting analysis demonstrated that mechanical vibration promoted gene and protein expression of canonical Wnt signaling genes, including Wnt3a, low-density lipoprotein receptor-related protein 6 and $\beta$-catenin. In conclusion, the present study demonstrated that mechanical vibration stimulates osteoblastic activities and may function through a potential canonical Wnt signaling-associated mechanism. These findings provided novel information that improves the understanding of the molecular mechanisms involved in osteoblastic activities in response to mechanical vibration, which may facilitate the scientific application of mechanical vibration for the treatment of osteoporosis in the clinic.

\section{Introduction}

The skeleton has the capacity to continuously remodeling its own mass and architecture in response to external mechanical stimuli $(1,2)$. It is well established that increased mechanical loading, such as through exercise or resistance training, may promote bone formation $(1,3)$, and that loss of weight-bearing activities (prolonged bed rest or microgravity) causes a significant decrease in bone mass and bone strength (4). The process of mechanical loading that regulates bone quality and bone remodeling involves the coordinated action of bone-resorbing osteoclasts and bone-forming osteoblasts (5). However, the mechanisms by which the skeleton and bone cells sense and transduce external mechanical stimulation have not yet been fully elucidated. Understanding the mechanisms of bone mechanotransduction and mechanobiology is significant for determining the etiology of osteoporosis, which may potentially lead to improved treatment of clinically-associated bone diseases.

Since the findings by Rubin et al (6) demonstrating the enhancement of bone mass in normal and osteoporotic animals following low-intensity, high-frequency whole-body vibration (WBV) in 2001 (7), numerous studies and increasing experimental evidence substantiates that WBV may be able to improve bone microarchitecture and regulate bone metabolism (8-14). In addition, several clinical investigations have indicated the positive effect of WBV on promoting bone mass in normal and osteoporosis patients $(11,14)$. Compared with traditional physical exercise, WBV demonstrates prominent 
superiority, as it is simple, safe, convenient and noninvasive. Despite observing significant inhibitory effects of WBV on osteopenia/osteoporosis, no explicit mechanisms have yet been established that explain WBV-induced regulation of bone remodeling. It has been speculated that WBV may affect bone cells via vibration-induced direct bone matrix strain (15) or interstitial fluid shear stress (16). Despite these plausible experimental hypotheses and promising conclusions concerning mechanical vibration-induced bone tissue transfer to individual cells, it remains necessary to explore the responses of osteoblasts directly subjected to WBV stimulation in vitro. This has the potential to increasing the understanding of how bone cells respond to mechanical vibration, and may therefore provide additional scientific applications of mechanical vibration for the treatment of osteoporosis in the clinic.

The canonical Wnt signaling pathway, also known as the Wnt/ $\beta$-catenin pathway, has been implicated in promoting osteoblastic differentiation and proliferation, and inhibiting osteoblastic apoptosis $(17,18)$. Extracellular Wnt proteins bind to the Frizzled and low-density lipoprotein receptor-related protein (Lrp) 5/6 co-receptors on the cell membrane, which subsequently leads to the stabilization of $\beta$-cateninin the cytoplasm, and may promote further Wnt-targeted gene transcription in the cell nucleus. Substantial evidence has indicated that activation of the canonical Wnt signaling pathway has the capacity of enhancing the expression of osteogenesis-associated cytokines, including bone morphogenetic protein 2 (BMP2) and Runt-related transcription factor 2 (Runx2) (19,20). Previous studies have demonstrated that Wnt, Lrp6 or $\beta$-catenin gene knockout mice exhibit an abnormal bone remodeling phenotype (21-23). Therefore, accumulating evidence confirms the essential role of the canonical Wnt signaling pathway in promoting osteoblastogenesis and regulating bone remodeling $(21,24-26)$. However, it remains necessary to investigate the role of the canonical Wnt signaling in WBV-regulated osteogenesis and bone anabolism.

In the present study, the effects of mechanical vibration on cell proliferation, mineralization, cytoskeletal microarchitecture and osteogenesis-associated gene and protein expression in primary newborn rabbit calvarial osteoblasts was systematically investigated. In addition, the impact of mechanical vibration on the gene and protein expression levels of the canonical Wnt signaling in primary osteoblasts was examined.

\section{Materials and methods}

In vitro mechanical loading devices. A custom-designed mechanical vibration system was employed in the present study to generate low-intensity and high-frequency loads to primary osteoblasts in vitro (Fig. 1A). For in vitro mechanical loading, cell culture plates containing primary osteoblasts were placed on the platform $(30 \times 30 \times 30 \mathrm{~cm})$. An electromagnetic actuator (Shanghai Huixia Instrument Co., Ltd., Shanghai, China) controlled by a function generator (Shanghai Huixia Instrument Co., Ltd.) was mounted beneath the platform to generate the vertical vibratory motion. An accelerometer (VIB-5; Shanghai Xinsheng Detecting Instrument Co., Ltd., Shanghai, China) was attached to the vibration platform to measure the mechanical signals transmitted to the cells. The machine generating systems imposed the vibration loading on osteoblasts in vitro at a sinusoidal waveform $\left(0.5 \mathrm{~g}_{\mathrm{n}}, 45 \mathrm{~Hz}\right)$.

Cell culture of primary osteoblasts. All procedures in the experiment were approved by the Institutional Animal Care and Use Committee of the Fourth Military Medical University. A total of five one-day-old New Zealand rabbits were euthanized with $\mathrm{CO}_{2}$, and primary osteoblasts were obtained by digesting the calvarial bone of the rabbits (Animal Center of the Fourth Military Medical University, Xi'an, China) according to the procedures described previously (27). Cells were maintained in $\alpha$-minimum essential medium (Hyclone; GE Healthcare Life Sciences, Logan, UT, USA) containing $10 \%$ fetal bovine serum (Hyclone; GE Healthcare Life Sciences) and $1 \%$ penicillin/streptomycin (Hyclone; GE Healthcare Life Sciences) at $37^{\circ} \mathrm{C}$. Primary rabbit osteoblasts were identified via Alizarin Red staining for mineralization nodules, using methods described previously (28). Cells at passage 3-6 were used in the experiment. Cells were seeded onto the 6-well plate for $12 \mathrm{~h}$ at $37^{\circ} \mathrm{C}$. Cells in the mechanical vibration group were subjected to $1 \mathrm{~h}$ /day mechanical vibratory stimulation for 3 consecutive days at room temperature. Cells in the control group were simultaneously placed onto the inactivated mechanical loading platform.

In vitro osteoblastic cytoskeletal morphology. Primary rabbit osteoblasts were seeded $(1 \mathrm{ml})$ into a $35 \mathrm{~mm}$ confocal laser dish at a density of $1 \times 10^{5}$ cells $/ \mathrm{ml}$. One dish constituted one sample. Following mechanical vibration stimulation, primary osteoblastic cells were fixed in $4 \%$ formaldehyde solution for $5 \mathrm{~min}$ and then permeabilized with $0.1 \%$ Triton $\mathrm{X}-100$ to evaluate osteoblastic cytoskeletal morphology. Cells were then stained with $50 \mathrm{mg} / \mathrm{ml}$ phalloidin-fluorescein isothiocyanate (FITC) (Sigma-Aldrich; Merck Millipore, Darmstadt, Germany) for $40 \mathrm{~min}$ and DAPI (Beyotime Institute of Biotechnology, Haimen, China) for $10 \mathrm{~min}$ to visualize the cytoskeletal microstructure and the cell nuclei. Following washing with PBS, cells were visualized using a confocal laser scanning microscope (FluoView FV1000; Olympus Corporation, Tokyo, Japan). A total of 10 fields of view of cells were visualized for each dish.

In vitro osteoblastic proliferation. For the proliferation assay, osteoblast suspensions were seeded into 96-well culture plates at a density of $1 \times 10^{4}$ cells/ml (200 $\left.\mu \mathrm{l} / \mathrm{well}\right)$ and cultured for $12 \mathrm{~h}$ to ensure sufficient adhesion to the cell culture plate. One well of a culture plate taken as one sample. Following mechanical vibration stimulation for 3 days, a Cell Counting Kit-8 (CCK-8) assay (Nanjing EnoGene Biotech. Co., Ltd., Nanjing, China) was used to quantify osteoblastic proliferation according to the provided manufacturer's instructions. Briefly, each well of the plate was supplemented with $20 \mu \mathrm{l} \mathrm{CCK}-8$ solution, and incubated at $37^{\circ} \mathrm{C}$ for $2 \mathrm{~h}$. The cell culture plate was then shaken for $1 \mathrm{~min}$ and the optical density values were examined with a microplate reader at $450 \mathrm{~nm}$ wavelength (TecanInfinite M200 Pro; Tecan Trading AG, Zurich, Switzerland).

In vitro osteoblastic osteogenesis-associated gene expression. Primary rabbit osteoblasts were seeded $(2 \mathrm{ml})$ onto a 6 -well 
A

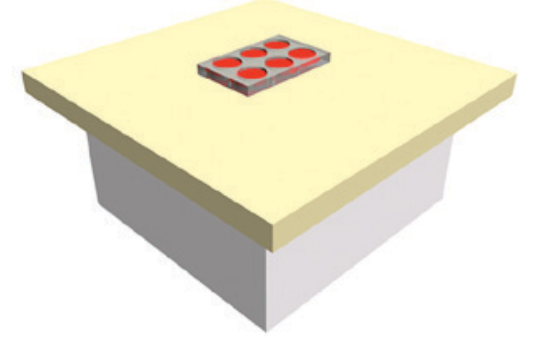

Mechanical vibration device
B

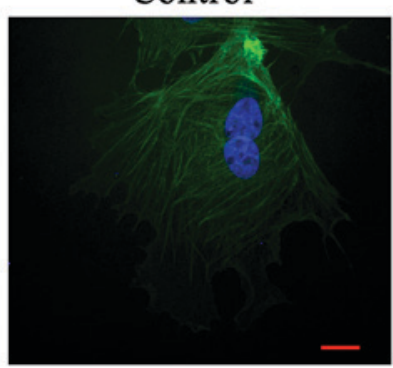

Control
Vibration

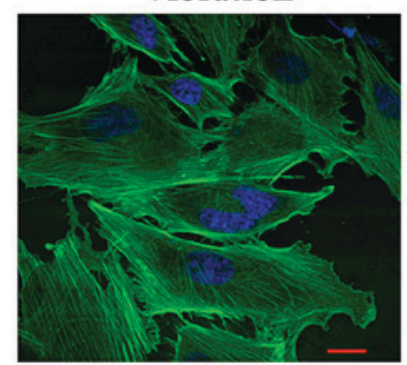

C

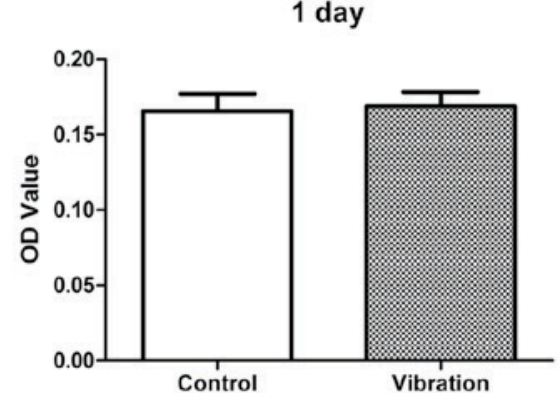

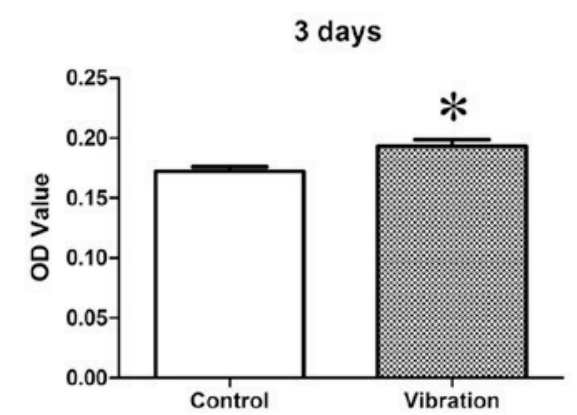

Figure 1. Effects of mechanical vibration on the cytoskeleton and proliferation of primary rabbit osteoblasts. (A) Schematic representation of the mechanical vibration generator. For the in vitro experiment, a cell culture dish containing primary osteoblasts was placed on the platform ( $30 \mathrm{x} 30 \mathrm{x} 30 \mathrm{~cm})$. The vertical vibratory motion was generated by an electromagnetic actuator mounted beneath the platform. The system generated a sinusoidal waveform with a vertical acceleration of $0.5 \mathrm{~g}$ at a frequency of $45 \mathrm{~Hz}$. (B) Representative images of phalloidin-fluorescein isothiocyanate cytoskeleton staining of primary osteoblasts in vitro in the control and mechanical vibration groups (Scale bar, $20 \mu \mathrm{m}$ ). (C) Mechanical vibration for 3 days significantly promoted osteoblastic proliferation, as demonstrated using Cell Counting Kit- 8 assay analysis $(\mathrm{n}=10)$. Values are expressed as the mean \pm standard deviation, ${ }^{*} \mathrm{P}<0.05$ vs. control. OD, optical density.

culture plate at a density of $1 \times 10^{5}$ cells $/ \mathrm{ml}$. A single well of a 6-well culture plate constituted one sample. Total RNA was isolated from the primary osteoblasts using TRIzol (Invitrogen, Thermo Fisher Scientific, Inc., Waltham, MA, USA) and quantified with a spectrophotometer (SmartSpec Plus; Bio-Rad Laboratories, Inc., Hercules, CA, USA). RNA $(2 \mu \mathrm{g})$ was reverse-transcribed into cDNA in a $40 \mu \mathrm{l}$ system with oligo $(\mathrm{dT})_{18}$ primers using the FastQuant RT kit (Tiangen Biotech Co., Ltd., Beijing, China). Reverse transcription-quantitative polymerase chain reaction (RT-qPCR) was performed using $2 \mu \mathrm{l}$ cDNA in a $20 \mu \mathrm{l}$ reaction system with Maxima SYBR-Green qPCR Master Mix (Thermo Fisher Scientific, Inc.) using the Bio-Rad CFX96 Real-Time PCR Detection system (Bio-Rad Laboratories, Inc.). The primer sequences utilized for RT-qPCR analyses are shown in Table I. The thermal cycling parameters for RT-qPCR reactions consisted of an initial denaturation step at $95^{\circ} \mathrm{C}$ for $10 \mathrm{~min}$ followed by 40 cycles of denaturation at $95^{\circ} \mathrm{C}$ for $15 \mathrm{sec}$, annealing at $55^{\circ} \mathrm{C}$ for $15 \mathrm{sec}$ and extension at $55^{\circ} \mathrm{C}$ for $15 \mathrm{sec} . \beta$-actin was used as an internal control for normalization. The relative quantity of mRNA was calculated using $2^{-\Delta \Delta C q}$ analysis (29). All RT-qPCR reactions were performed in triplicate.

In vitro osteoblastic osteogenesis-associated protein expression. Primary rabbit osteoblasts were seeded $(2 \mathrm{ml})$ into a 6 -well culture plates at a density of $1 \times 10^{5}$ cells $/ \mathrm{ml}$. A single well of a 6 -well culture plate constituted a sample. The adherent primary osteoblasts were washed with ice-cold PBS and lysed to obtain total protein using radioimmunoprecipitation assay buffer containing $1 \mathrm{mM}$ phenylmethylsulfonyl fluoride (Sigma-Aldrich; Merck Millipore). The cell lysates were agitated at $4^{\circ} \mathrm{C}$ for $30 \mathrm{~min}$ and then centrifuged at $4^{\circ} \mathrm{C}$ for $20 \mathrm{~min}$ at $30,000 \mathrm{x}$. The protein concentration was determined using a bicinchoninic assay kit (Pierce; Thermo Fisher Scientific, Inc.). The protein extracts ( $30 \mu \mathrm{g}$ per sample) were separated by 8 or $10 \%$ Tris-glycine SDS-PAGE and then transferred onto PVDF membranes (EMD Millipore, Billerica, MA, USA) after mixing with $2 \mathrm{X}$ loading buffer. The polyvinylidene difluoride membranes were blocked in TBS $0.5 \%$ Tween-20 (TBST) containing 5\% bovine serum albumin (BSA) for $1 \mathrm{~h}$ at room temperature and incubated overnight at $4^{\circ} \mathrm{C}$ with primary antibodies. The primary antibodies are listed as follows: Mouse anti-rabbit monoclonal osteocalcin (OCN; dilution, 1:1,000; cat. no. ab13420; Abcam, Cambridge, MA, USA), mouse anti-rabbit monoclonal Runx2 (dilution, 1:1,000; cat. no. BA3613-2; Wuhan Boster Biological Technology, Ltd., Wuhan, China), rabbit polyclonal anti-rabbit Wnt3a (dilution, 1:300; cat. no. bs-23278R; Bioss, Beijing, China), mouse monoclonal anti-rabbit Lrp6 (dilution, 1:300; cat. no. bs-2905R; Bioss), rabbit polyclonal anti-rabbit $\beta$-catenin (1:1,000; cat. no. 06-734; EMD Millipore) and mouse monoclonal anti-rabbit GAPDH (1:3,000, cat. no. MB001; Bioworld Technology, Inc., St. Louis Park, MN, USA) antibodies. All primary antibodies were diluted in TBST containing 5\% BSA. The membranes were then incubated with a 1:3,000 dilution of horseradish peroxidase-conjugated secondary antibody (cat. no. BA1051; Wuhan Boster Biological Technology, Ltd.) for $1 \mathrm{~h}$ at room temperature, and visualized using an enhanced chemiluminescence system (ImageQuant 350; GE Healthcare Life Sciences, Chalfont, UK). Semi-quantitative analysis 
Table I. The sequence of primers used in the present study for in vitro reverse transcription-quantitative polymerase chain reaction.

\begin{tabular}{|c|c|c|c|}
\hline Gene & $\begin{array}{l}\text { Primer } \\
\text { direction }\end{array}$ & Primer sequence $\left(5^{\prime}-3^{\prime}\right)$ & $\begin{array}{l}\text { Product } \\
\text { length (bp) }\end{array}$ \\
\hline ALP & $\begin{array}{l}\text { Forward } \\
\text { Reverse }\end{array}$ & $\begin{array}{l}\text { ACGGGGCGTGTATCCTCCAA } \\
\text { CCCAAGGAGGCAGGATTGAC }\end{array}$ & 182 \\
\hline $\mathrm{OCN}$ & $\begin{array}{l}\text { Forward } \\
\text { Reverse }\end{array}$ & $\begin{array}{l}\text { TTGGTGCACACCTAGCAGAC } \\
\text { ACCTTATTGCCCTCCTGCTT }\end{array}$ & 187 \\
\hline Runx-2 & $\begin{array}{l}\text { Forward } \\
\text { Reverse }\end{array}$ & $\begin{array}{l}\text { CAGTCTTACCСCTCTTACC } \\
\text { CATCTTTACCTGAAATGCG }\end{array}$ & 130 \\
\hline BMP2 & $\begin{array}{l}\text { Forward } \\
\text { Reverse }\end{array}$ & $\begin{array}{l}\text { GGACGACATCCTGAGCGAGT } \\
\text { CGGCGGTACAAGTCCAGCAT }\end{array}$ & 117 \\
\hline SOST & $\begin{array}{l}\text { Forward } \\
\text { Reverse }\end{array}$ & $\begin{array}{l}\text { TCTCCCTAGCCCTGTGTCTCCT } \\
\text { ACTTCCGTGGCGTCATTCTTGA }\end{array}$ & 100 \\
\hline Wnt3a & $\begin{array}{l}\text { Forward } \\
\text { Reverse }\end{array}$ & $\begin{array}{l}\text { ATGAACCGCCACAACAAC } \\
\text { GCTTCTCCACCACCATCT }\end{array}$ & 190 \\
\hline Lrp6 & $\begin{array}{l}\text { Forward } \\
\text { Reverse }\end{array}$ & $\begin{array}{l}\text { GCTTGGCACTTGTATGTAAA } \\
\text { TGGGCTAAGATCATCAGACT }\end{array}$ & 179 \\
\hline$\beta$-catenin & $\begin{array}{l}\text { Forward } \\
\text { Reverse }\end{array}$ & $\begin{array}{l}\text { GACACGGACCACACGCACAA } \\
\text { CCGAGCAGCAGCAAGTCTTCT }\end{array}$ & 173 \\
\hline OPG & $\begin{array}{l}\text { Forward } \\
\text { Reverse }\end{array}$ & $\begin{array}{l}\text { AACGGCGGCATAGTTCACAAGA } \\
\text { GCTGCGAAGCTGATCCAAGGT }\end{array}$ & 170 \\
\hline$\beta$-actin & $\begin{array}{l}\text { Forward } \\
\text { Reverse }\end{array}$ & $\begin{array}{l}\text { TACGCCAACACGGTGCTGTC } \\
\text { ACATCTGCTGGAAGGTGGAGAG }\end{array}$ & 187 \\
\hline
\end{tabular}

ALP, alkaline phosphatase; OCN, osteocalcin; Runx2, Runt-related transcription factor 2; BMP2, bone morphogenetic protein 2; SOST, sclerostin; Lrp6, low-density lipoprotein receptor-related protein 6; OPG, osteoprotegerin.

was performed using the QuantityOne software (version 4.5; Bio-Rad Laboratories, Inc.). GAPDH was used as an internal control for normalization.

In vitro osteoblastic mineralization. Primary rabbit osteoblasts were seeded $(2 \mathrm{ml})$ onto a 6 -well culture plate at a density of $1 \times 10^{5}$ cells $/ \mathrm{ml}$. Osteoblastic mineralization was determined using a quantitative Alizarin Red-S staining procedure, as previously described $(30,31)$. One well of a 6-well culture plate was used as one sample. Following mechanical vibration stimulation for 14 consecutive days ( $1 \mathrm{~h}$ /day), the plates containing primary osteoblasts were fixed with $4 \%$ paraformaldehyde and then stained with $40 \mathrm{mM}$ Alizarin Red-S (Sigma-Aldrich; Merck Millipore) for $1 \mathrm{~h}$. Following rinsing with PBS, the bound stain was eluted using $0.5 \mathrm{ml}$ of $5 \%$ cetylpyridinium chloride. The solubilized stain $(0.15 \mathrm{ml})$ was transferred to a 96-well plate, and the absorbance values were determined at $405 \mathrm{~nm}$ with a multimode microplate reader (Tecan Infinite M200 Pro; Tecan Trading AG).

Statistical analysis. All data presented in this study areexpressed as the mean \pm standard deviation. Statistical analyses were performed using SPSS (version 13.0; SPSS, Inc., Chicago, IL, USA). The differences of each parameter between the control group and mechanical vibration group were examined using a Student's t-test. $\mathrm{P}<0.05$ was considered to indicate a statistically significant difference.

\section{Results}

In vitro osteoblastic proliferation and morphology. Primary rabbit osteoblasts exhibited a fusiform, triangle or polygonal shape, with a round or oval nucleus, and demonstrated positive staining of mineralization nodules (data not shown). Phalliodin-FITC cytoskeleton staining images (Fig. 1B) demonstrated that osteoblasts in the mechanical vibration group displayed a well-developed cytoskeleton with higher fluorescence intensity, and increased number of microfilaments with directional arrangement, and thicker stress fibers compared with the cells in the control group. As presentedin Fig. 1C, a significant increase in osteoblastic proliferation was observed following mechanical vibration stimulation for 3 days via CCK-8 assay analysis $(\mathrm{P}=0.0003)$, whereas no obvious increase was observed following 1 day of mechanical vibration compared with the control group.

In vitro osteogenesis-associated gene expression. As indicated in Fig. 2, mechanical vibration significantly increased alkaline phosphatase (ALP), osteocalcin (OCN), Runx2, BMP2 and osteoprotegerin (OPG) mRNA expression compared with the control group $(\mathrm{P}=0.0017,0.0362,0.0001,0.0091$ and 0.0017 , respectively). In addition, mechanical vibration significantly decreased sclerostin (SOST) gene expression levels compared with the control group $(\mathrm{P}=0.0001)$. The gene expression levels of canonical Wnt signaling pathway members, including 
ALP

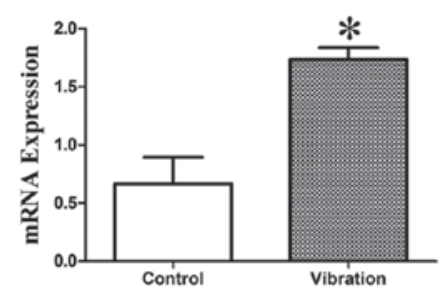

BMP2

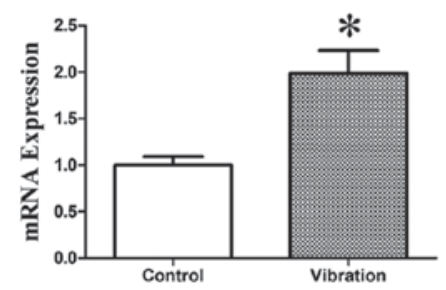

Wnt3a

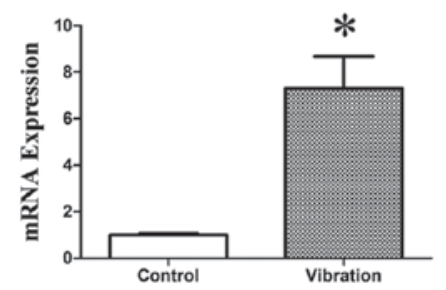

OCN

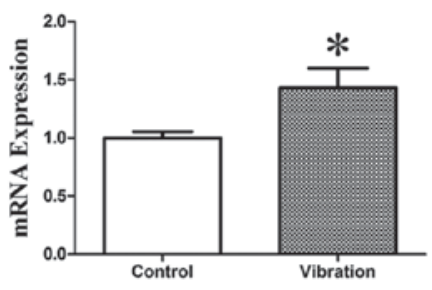

OPG

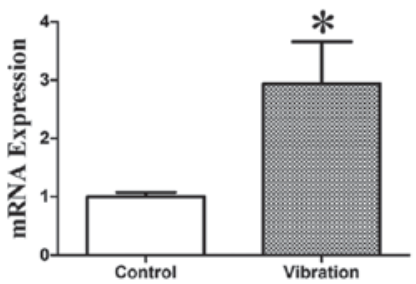

$\beta$-catenin

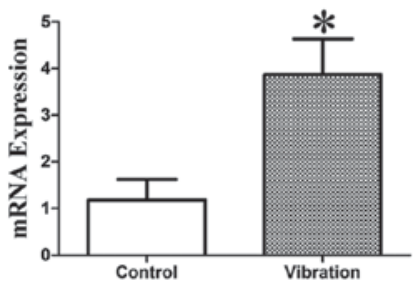

Runx2

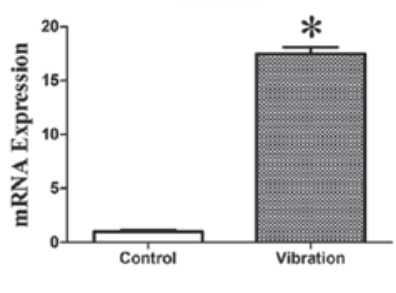

SOST

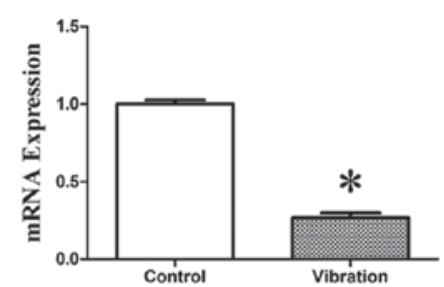

Lrp6

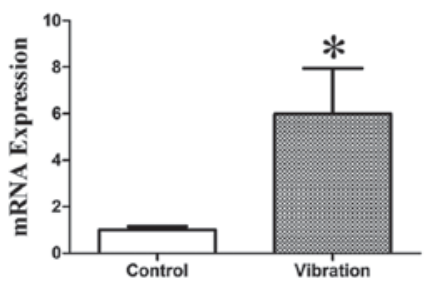

Figure 2. Effects of in vitro mechanical vibration stimulation on osteogenesis-associated gene expression in primary rabbit osteoblasts. Reverse transcription-quantitative polymerase chain reaction analysis of ALP, OCN, Runx2, BMP2, OPG, SOST, Wnt3a, Lrp6 and $\beta$-catenin gene expression levels. Values are expressed as the mean \pm standard deviation. $(n=3)$. The relative expression level of each gene was normalized to $\beta$-actin, ${ }^{*} \mathrm{P}<0.05$ vs. control. ALP, alkaline phosphatase; OCN, osteocalcin; Runx2, Runt-related transcription factor 2; BMP2, bone morphogenetic protein 2; OPG, osteoprotegerin; SOST, sclerostin; Lrp6, low-density lipoprotein receptor-related protein 6.

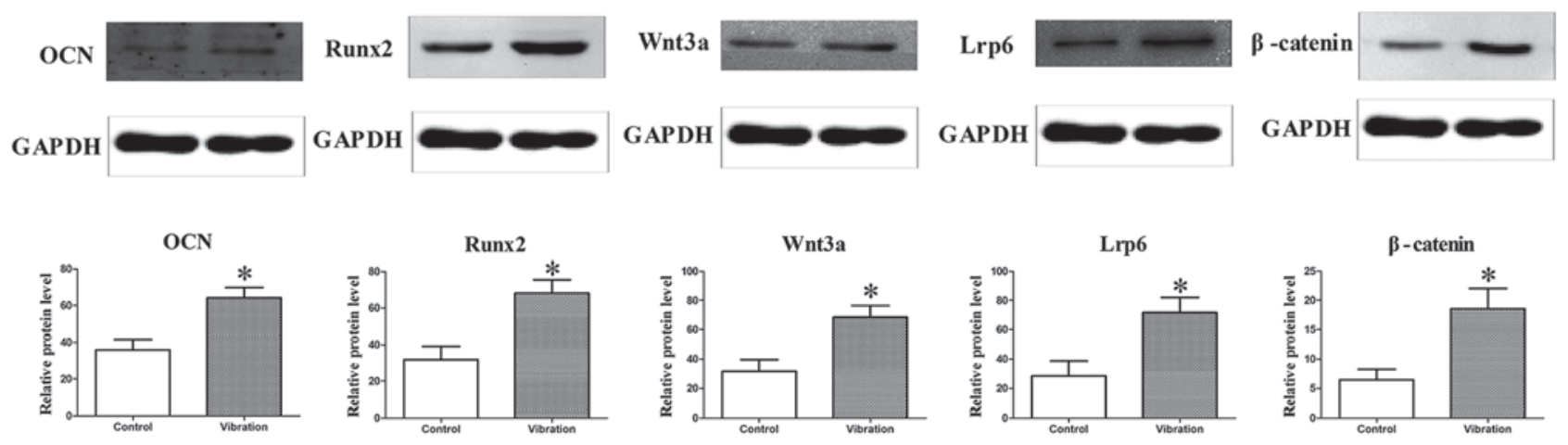

Figure 3. Effects of in vitro mechanical vibration stimulation on osteogenesis-associated protein expression in primary rabbit osteoblasts. The expression levels of OCN, Runx2, Wnt3a, Lrp6 and $\beta$-catenin were examined via western blotting analysis. Values are expressed as the mean \pm standard deviation (n=3-4). The relative expression level of each gene was normalized to GAPDH. * $\mathrm{P}<0.05$ vs. control. OCN, osteocalcin; Runx2, Runt-related transcription factor 2; Lrp6, low-density lipoprotein receptor-related protein 6.

Wnt3a, Lrp6 and $\beta$-catenin were significantly higher in the mechanical vibration group compared with the control group $(\mathrm{P}=0.0103,0.0454$ and 0.0372 , respectively).

In vitro osteogenesis-associated protein expression. As demonstrated in Fig. 3, western blotting results revealed that mechanical vibration stimulation significantly stimulated the protein expression of osteogenesis-associate factors, including OCN and Runx2 ( $\mathrm{P}=0.0034$ and 0.0004 , respectively). In addition, the protein expression levels of members of the canonical Wnt signaling pathway, including Wnt3a, Lrp6 and $\beta$-catenin, were significantly higher in the mechanical vibration group compared with the control group $(\mathrm{P}=0.0051,0.0008$ and 0.0011 , respectively).

Extracellular matrix (ECM) mineralization. As presented in Fig. 4, ECM mineralization was determined via Alizarin Red staining, which revealed an increased area of mineralization 
A

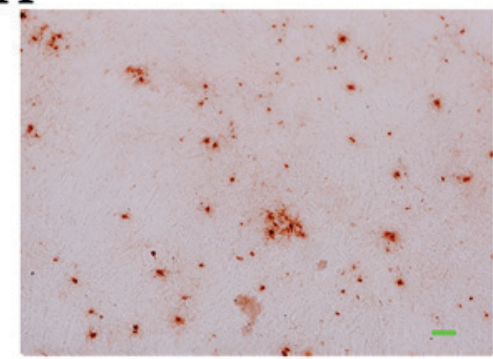

Control

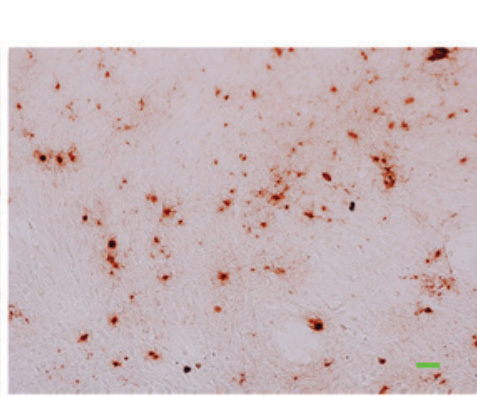

Vibration
B

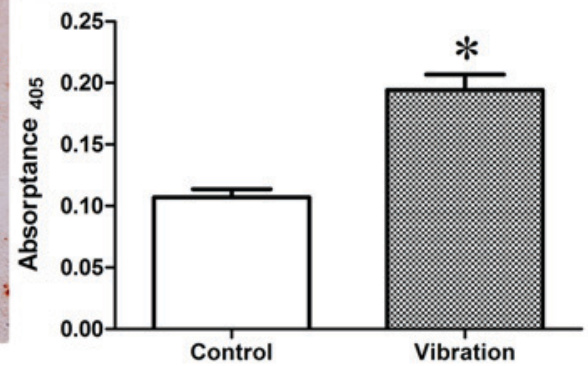

Figure 4. Effects of mechanical vibration stimulation on extracellular matrix mineralization in primary rabbit osteoblasts via Alizarin Red staining. (A) Representative microscope images (magnification, $\mathrm{x} 4$ ) of Alizarin Red-stained osteoblasts in the control and mechanical vibration groups (Scale bar, $20 \mu \mathrm{m}$ ). (B) Quantitative comparisons of absorbance values of the solubilized stain in the control and mechanical vibration groups. Values are expressed as the mean \pm standard deviation, $(\mathrm{n}=10)$. ${ }^{*} \mathrm{P}<0.05$ vs. control.

in the mechanical vibration group with a higher number of stained nodules, compared with the controls. Quantification of the solubilized stain demonstrated that ECM mineralization was significantly increased following mechanical vibration stimulation compared with the control group $(\mathrm{P}=0.0001)$.

\section{Discussion}

WBV, as a promising, safe and non-pharmacological therapy, has been demonstrated to promote osteogenesis experimentally and clinically $(14,32)$. However, the exact regulatory mechanisms underlying the effect of WBV exposure on osteogenesis and bone remodeling remains poorly understood. Therefore, to evaluate the mechanism of mechanical vibration as a potential treatment modality for osteoporosis, it is vital to assess its impact on osteoblasts in vitro as a scientific reference for subsequent clinically therapeutic applications. In the present study, mechanical vibration $(45 \mathrm{~Hz}, 0.5 \mathrm{~g})$ was applied for $1 \mathrm{~h} /$ day as the stimulation parameter, which is consistent with the parameter used by Judex et al (3). The results of the current study demonstrated that mechanical vibration significantly increased osteoblastic proliferation and mineralization, and induced the formation of a well-arranged cytoskeletal structure. Furthermore, these results that the expression of osteogenesis-associated molecules, including ALP, OCN, Runx2 and BMP2, was significantly increased by mechanical vibration. Notably, mechanical vibration significantly enhanced the gene and protein expression levels of canonical Wnt/ $\beta$-catenin signaling pathway members, indicating that canonical Wnt signaling may be involved in the regulation of mechanical vibration-induced osteoblastogenesis. These results provide a novel insight into the application of mechanical vibration for promoting osteogenesis. In addition, these results extend the basic knowledge of the molecular mechanisms involved in osteoblastic functions in response to external mechanical signals.

As demonstrated in the current study, the activities of osteoblasts were significantly stimulated when they were subjected to mechanical vibration $(45 \mathrm{~Hz}, 0.5 \mathrm{~g}$ ) for $1 \mathrm{~h}$ /day for 3 days. The results of CCK-8 analysis and quantitative Alizarin Red-S staining revealed that the proliferation and mineralization of primary osteoblasts were promoted under mechanical vibration. The results are consistent with the findings of Chow et al (33). In addition, these results revealed obvious cytomorphological alterations to osteoblasts in vitro following 3 days of micromechanical vibration stimulation. Similarly, these results are consistent with several previous findings $(34,35)$ that observed a higher number of and thicker microfilaments in the osteoblastic cytoskeleton with directional arrangement following stimulation by mechanical vibration (36). Furthermore, the cytoskeleton adjusts its structure in response to external physical or chemical stimuli and intracellular biochemical events (37). It has been demonstrated that cytoskeletal deformation is one of the earliest events that occurs following exposure of bone cells to external biophysical stimuli, and thus modulates the intracellular biochemical response and the subsequent osteogenic activities $(38,39)$. Together, the findings of the present study confirm that mechanical vibration may regulate osteoblastic cytoskeletal microstructure and enhance osteoblastic proliferation and mineralization.

To explore the mechanism by which mechanical vibration regulates osteoblastic activities in vitro, the gene and protein expression levels of osteogenesis-associated molecules and signaling pathways were investigated. In the current study, the results indicated that the gene expression of ALP, a marker of the osteoblast phenotype, was upregulated following mechanical vibration, which is consistent with previous findings (40). It was identified that vibratory loading increased the gene and protein expression levels of $\mathrm{OCN}$, a major osteoblastic differentiation and bone formation marker, which was similar to results of a previous study by Tanaka et al (40). In addition, mechanical vibration was observed to lead to upregulation of the gene and protein levels of Runx 2, a key transcription factor involved in osteoblast differentiation (41). The gene expression levels of BMP2 and OPG, two molecules responsible for regulating osteoblast differentiation and inhibiting osteoclast activities $(42,43)$, were observed to be upregulated following mechanical vibration stimulation in the present study. Additionally, a significant downregulation in SOST gene expression was identified. The SOST gene encodes the sclerostin protein, which was previously hypothesized to be a negative regulator of bone formation and exclusively expressed by osteocytes (44-46). It has been demonstrated that sclerostin functions as a BMP antagonist and is an inhibitor of the canonical Wnt signaling pathway (47). 
Accumulating evidence has identified that canonical Wnt signaling serves a key role in regulating osteogenesis, and ultimately regulates bone mass and bone strength $(48,49)$. Extracellular Wnt proteins initially bind to the Frizzled and Lrp5/6 co-receptors on the cell membrane, which results in the stabilization of $\beta$-catenin in the cytoplasm and facilitates further Wnt-targeted gene transcription in the cell nucleus. It has been demonstrated that activation of canonical Wnt signaling can promote osteoblastogenesis and enhance osteoblast activity (50-52). Knockout of genes involved in the canonical Wnt signaling pathway in mice, including Wnt, Lrp6 and $\beta$-catenin exhibited abnormal bone remodeling and decreased bone mass $(52,53)$. In addition, it was demonstrated that canonical Wnt signaling activates ALP, Runx2 and BMP2 expression $(19,20,54)$. The findings of the present study indicated that the gene and protein expression levels of genes involved in the Wnt signaling pathway were significantly enhanced in osteoblasts in vitro following mechanical stimulation. Thus, these results demonstrated that the activation of the canonical Wnt signaling pathway may have an essential role in mediating mechanical vibration-induced osteoblastogenesis.

In conclusion, the results of the current study indicated that mechanical vibration stimulation $\left(0.5 \mathrm{~g}_{\mathrm{n}}, 45 \mathrm{~Hz}\right)$ positively regulated the biological functions of osteoblasts, as characterized by changes in cytoskeletal microstructure, enhancement of cellular proliferation and augmentation of bone matrix mineralization. In addition, these results demonstrated that mechanical vibration promoted osteogenesis-associated gene and protein expression and activated canonical Wnt signaling pathway. It was revealed that low-level mechanical vibration enhanced osteoblastogenesis through a potential canonical Wnt signaling-associated mechanism. This study increases the basic knowledge of the osteogenic activity of WBV, and may contribute to a more efficient and scientific clinical application of WBV in promoting osteogenesis and inhibiting osteoporosis.

\section{Acknowledgements}

The authors acknowledge the support from the National Natural Science Foundation of China (grant nos. 81471806 and 31270889), the Natural Science Foundation of Shaanxi Province (grant no. 2014JQ4139), and the Doctoral Thesis Foundation of the Fourth Military Medical University (grant no. 2015D13).

\section{References}

1. Xie L, Jacobson JM, Choi ES, Busa B, Donahue LR, Miller LM, Rubin CT and Judex S: Low-level mechanical vibrations can influence bone resorption and bone formation in the growing skeleton. Bone 39: 1059-1066, 2006.

2. Xie P, Tang Z, Qing F, Chen X, Zhu X, Fan Y, Yang X and Zhang X: Bone mineral density, microarchitectural and mechanical alterations of osteoporotic rat bone under long-term whole-body vibration therapy. J Mech Behav Biomed Mater 53: 341-349, 2015

3. Judex S, Lei X, Han D and Rubin C: Low-magnitude mechanical signals that stimulate bone formation in the ovariectomized rat are dependent on the applied frequency but not on the strain magnitude. J Biomech 40: 1333-1339, 2007.

4. Jing D, Cai J, Wu Y, Shen G, Li F, Xu Q, Xie K, Tang C, Liu J, Guo W, et al: Pulsed electromagnetic fields partially preserve bone mass, microarchitecture, and strength by promoting bone formation in hindlimb-suspended rats. J Bone Miner Res 29: 2250-2261, 2014.
5. Garnero P: New developments in biological markers of bone metabolism in osteoporosis. Bone 66: 46-55, 2014.

6. Rubin C, Turner AS, Bain S, Mallinckrodt C and McLeod K: Anabolism. Low mechanical signals strengthen long bones. Nature 412: 603-604, 2001

7. Rubin $\mathrm{C}, \mathrm{Xu} \mathrm{G}$ and Judex $\mathrm{S}$ : The anabolic activity of bone tissue, suppressed by disuse, is normalized by brief exposure to extremely low-magnitude mechanical stimuli. FASEB J 15: 2225-2229, 2001.

8. Judex S, Donahue LR and Rubin C: Genetic predisposition to low bone mass is paralleled by an enhanced sensitivity to signals anabolic to the skeleton. FASEB J 16: 1280-1282, 2002.

9. Chan ME, Adler BJ, Green DE and Rubin CT: Bone structure and B-cell populations, crippled by obesity, are partially rescued by brief daily exposure to low-magnitude mechanical signals. FASEB J 26: 4855-4863, 2012.

10. Sehmisch S, Galal R, Kolios L, Tezval M, Dullin C, Zimmer S, Stuermer KM and Stuermer EK: Effects of low-magnitude, high-frequency mechanical stimulation in the rat osteopenia model. Osteoporos Int 20: 1999-2008, 2009.

11. Gilsanz V, Wren TA, Sanchez M, Dorey F, Judex S and Rubin C: Low-level, high-frequency mechanical signals enhance musculoskeletal development of young women with low BMD. J Bone Miner Res 21: 1464-1474, 2006.

12. Shi HF, Cheung WH, Qin L, Leung AH and Leung KS: Low-magnitude high-frequency vibration treatment augments fracture healing in ovariectomy-induced osteoporotic bone. Bone 46: 1299-1305, 2010.

13. Christiansen BA and Silva MJ: The effect of varying magnitudes of whole-body vibration on several skeletal sites in mice. Ann Biomed Eng 34: 1149-1156, 2006.

14. Rubin C, Recker R, Cullen D, Ryaby J, McCabe J and McLeod K: Prevention of postmenopausal bone loss by a low-magnitude, high-frequency mechanical stimuli: A clinical trial assessing compliance, efficacy, and safety. J Bone Miner Res 19: 343-351, 2004.

15. Fritton SP, McLeod KJ and Rubin CT: Quantifying the strain history of bone: Spatial uniformity and self-similarity of low-magnitude strains. J Biomech 33: 317-325, 2000

16. Coughlin TR and Niebur GL: Fluid shear stress in trabecular bone marrow due to low-magnitude high-frequency vibration. J Biomech 45: 2222-2229, 2012.

17. Caetano-Lopes J, Canhão H and Fonseca JE: Osteoblasts and bone formation. Acta Reumatol Port 32: 103-110, 2007.

18. Jiang T, Zhou B, Huang L, Wu H, Huang J, Liang T, Liu H, Zheng L and Zhao J: Andrographolide exerts pro-osteogenic effect by activation of Wnt/ $\beta$-catenin signaling pathway in vitro. Cell Physiol Biochem 36: 2327-2339, 2015.

19. Gaur T, Lengner CJ, Hovhannisyan H, Bhat RA, Bodine PV, Komm BS, Javed A, van Wijnen AJ, Stein JL, Stein GS and Lian JB: Canonical WNT signaling promotes osteogenesis by directly stimulating Runx2 gene expression. J Biol Chem 280: 33132-33140, 2005.

20. Zhang R, Oyajobi BO, Harris SE, Chen D, Tsao C, Deng HW and Zhao M: Wnt/ $\beta$-catenin signaling activates bone morphogenetic protein 2 expression in osteoblasts. Bone 52: 145-156, 2013.

21. Bennett CN, Longo KA, Wright WS, Suva LJ, Lane TF, Hankenson KD and MacDougald OA: Regulation of osteoblastogenesis and bone mass by Wnt10b. Proc Natl Acad Sci USA 102: 3324-3339, 2005

22. Wang B, Jin H, Zhu M, Li J, Zhao L, Zhang Y, Tang D, Xiao G, Xing L, Boyce BF and Chen D: Chondrocyte beta-catenin signaling regulates postnatal bone remodeling through modulation of osteoclast formation in a murine model. Arthritis Rheumatol 66: 107-120, 2014

23. Li C, Wang W, Xie L, Luo X, Cao X and Wan M: Lipoprotein receptor-related protein 6 is required for parathyroid hormone-induced Sost suppression. Ann NYAcad Sci 1364: 62-73, 2016

24. Wang Y, Li YP, Paulson C, Shao JZ, Zhang X, Wu M and Chen W: Wnt and the Wnt signaling pathway in bone development and disease. Front Biosci (Landmark Ed) 19: 379-407, 2014.

25. Xu C, Wang J, Zhu T, Shen Y, Tang X, Fang L and Xu Y: Cross-talking between PPAR and WNT signaling and its regulation in mesenchymal stem cell differentiation. Curr Stem Cell Res Ther 11: 247-254, 2016.

26. Weivoda MM, Ruan M, Hachfeld CM, Pederson L, Howe A, Davey RA, Zajac JD, Kobayashi Y, Williams BO, Westendorf JJ, et al: Wnt signaling inhibits osteoclast differentiation by activating canonical and noncanonical cAMP/PKA pathways. J Bone Miner Res 31: 65-75, 2016. 
27. Wong GL and Cohn DV: Target cells in bone for parathormone and calcitonin are different: Enrichment for each cell type by sequential digestion of mouse calvaria and selective adhesion to polymeric surfaces. Proc Natl Acad Sci USA 72: 3167-3171, 1975.

28. Williams DC, Boder GB, Toomey RE, Paul DC, Hillman CC Jr, King KL, Van Frank RM and Johnston CC Jr: Mineralization and metabolic response in serially passaged adult rat bone cells. Calcif Tissue Int 30: 233-246, 1980.

29. Livak KJ and Schmittgen TD: Analysis of relative gene expression data using real-time quantitative PCR and the 2(-Delta Delta C(T)) Method. Methods 25: 402-408, 2001.

30. Shui $C$ and Scutt A: Mild heat shock induces proliferation, alkaline phosphatase activity, and mineralization in human bone marrow stromal cells and Mg-63 cells in vitro. J Bone Miner Res 16: 731-741, 2001.

31. Ciapetti G, Ambrosio L, Savarino L, Granchi D, Cenni E, Baldini N,Pagani S, Guizzardi S, Causa Fand Giunti A: Osteoblast growth and function in porous poly epsilon-caprolactone matrices for bone repair: A preliminary study. Biomaterials 24: 3815-3824, 2003.

32. Gori F, Hofbauer LC, Dunstan CR, Spelsberg TC, Khosla S and Riggs BL: The expression of osteoprotegerin and RANK ligand and the support of osteoclast formation by stromal-osteoblast lineage cells is developmentally regulated. Endocrinology 141: 4768-4776, 2000.

33. Chow SK, Leung KS, Qin J, Guo A, Sun M, Qin L and Cheung WH: Mechanical stimulation enhanced estrogen receptor expression and callus formation in diaphyseal long bone fracture healing in ovariectomy-induced osteoporotic rats. Osteoporos Int 27: 2989-3000, 2016.

34. Zhang C, Lu Y, Zhang L, Liu Y, Zhou Y, Chen Y and Yu H: Influence of different intensities of vibration on proliferation and differentiation of human periodontal ligament stem cells. Arch Med Sci 11: 638-646, 2015.

35. Uzer G, Pongkitwitoon S, Ete Chan M and Judex S: Vibration induced osteogenic commitment of mesenchymal stem cells is enhanced by cytoskeletal remodeling but not fluid shear. J Biomech 46: 2296-2302, 2013.

36. Sato N, Kubo K, Yamada M, Hori N, Suzuki T, Maeda H and Ogawa T: Osteoblast mechanoresponses on Ti with different surface topographies. J Dent Res 88: 812-816, 2009.

37. Thompson WR, Rubin CT and Rubin J: Mechanical regulation of signaling pathways in bone. Gene 503: 179-193, 2012

38. Huang H, Kamm RD and Lee RT: Cell mechanics and mechanotransduction: Pathways, probes, and physiology. Am J Physiol Cell Physiol 287: C1-C11, 2004.

39. Klein-Nulend J, Bacabac RG and Bakker AD: Mechanical loading and how it affects bone cells: The role of the osteocyte cytoskeleton in maintaining our skeleton. Eur Cell Mater 24: 278-291, 2012

40. Tanaka SM, Li J, Duncan RL, Yokota H, Burr DB and Turner CH: Effects of broad frequency vibration on cultured osteoblasts J Biomech 36: 73-80, 2003.
41. Otto F, Thornell AP, Crompton T, Denzel A, Gilmour KC, Rosewell IR, Stamp GW, Beddington RS, Mundlos S, Olsen BR, et al: Cbfa1, a candidate gene for cleidocranial dysplasia syndrome, is essential for osteoblast differentiation and bone development. Cell 89: 765-771, 1997.

42. Wozney JM, Rosen V, Celeste AJ, Mitsock LM, Whitters MJ, Kriz RW, Hewick RM and Wang EA: Novel regulators of bone formation: Molecular clones and activities. Science 242: $1528-1534,1988$

43. Hofbauer LC and Schoppet M: Clinical implications of the osteoprotegerin/RANKL/RANK system for bone and vascular diseases. JAMA 292: 490-495, 2004.

44. Bonewald LF: The amazing osteocyte. J Bone Miner Res 26: 229-238, 2011.

45. Burgers TA and Williams BO: Regulation of Wnt $/ \beta$-catenin signaling within and from osteocytes. Bone 54: 244-249, 2013.

46. Bellido T, Saini V and Pajevic PD: Effects of PTH on osteocyte function. Bone 54: 250-257, 2013.

47. Ellies DL, Viviano B, McCarthy J, Rey JP, Itasaki N, Saunders S and Krumlauf R: Bone density ligand, Sclerostin, directly interacts with LRP5 but not LRP5G171V to modulate Wnt activity. J Bone Miner Res 21: 1738-1749, 2006.

48. Santos A, Bakker AD, Zandieh-Doulabi B, Semeins CM and Klein-Nulend J: Pulsating fluid flow modulates gene expression of proteins involved in Wnt signaling pathways in osteocytes. J Orthop Res 27: 1280-1287, 2009.

49. Macsai CE, Foster BK and Xian CJ: Roles of Wnt signalling in bone growth, remodelling, skeletal disorders and fracture repair. J Cell Physiol 215: 578-587, 2008.

50. Zhang R, Oyajobi BO, Harris SE, Chen D, Tsao C, Deng HW and Zhao M: Wnt/ $\beta$-catenin signaling activates bone morphogenetic protein 2 expression in osteoblasts. Bone 52: 145-156, 2013.

51. Gaur T, Lengner CJ, Hovhannisyan H, Bhat RA, Bodine PV, Komm BS, Javed A, van Wijnen AJ, Stein JL, Stein GS and Lian JB: Canonical WNT signaling promotes osteogenesis by directly stimulating Runx2 gene expression. J Biol Chem 280: 33132-3340, 2005.

52. Bennett CN, Longo KA, Wright WS, Suva LJ, Lane TF, Hankenson KD and MacDougald OA: Regulation of osteoblastogenesis and bone mass by Wnt10b. Proc Natl Acad Sci USA 102: 3324-3329, 2005.

53. Wang B, Jin H, Zhu M, Li J, Zhao L, Zhang Y, Tang D, Xiao G, Xing L, Boyce BF and Chen D: Chondrocyte $\beta$-catenin signaling regulates postnatal bone remodeling through modulation of osteoclast formation in a murine model. Arthritis Rheumatol 66: 107-120, 2014.

54. Rawadi G, Vayssière B, Dunn F, Baron R and Roman-Roman S: BMP-2 controls alkaline phosphatase expression and osteoblast mineralization by a Wnt autocrine loop. J Bone Miner Res 18: 1842-1853, 2003. 